\title{
Vibration analysis: optimization of parameters of the two mass model based on Kelvin elements
}

\author{
A. Kuznetsov, M. Mammadov, I. Sultan, E. Hajilarov
}

\begin{abstract}
In this paper we consider the problem of finding optimal parameters of the two mass model that represents vehicle suspension systems. The analysis of the problem is based on finding analytical solution of the system of coupled Ordinary Differential Equations (ODE). Such a technique allows us to generate optimization problem, where an objective function should be minimized, in accordance with ISO 2631 standard formula of admissible acceleration levels. That ensures maximum comfort for a driver and passenger in a moving vehicle on the considered highways.
\end{abstract}

\section{INTRODUCTION AND LITERATURE REVIEW}

$\mathrm{I}_{\mathrm{p}}^{\mathrm{n}}$ $\mathrm{n}$ this paper we consider the problem of finding optimal parameters of the vehicle suspensions given roads with different profiles the driver or passenger could be exposed while the vehicle is driven on these roads.

Currently, there are many of publications on modelling vehicle suspensions, for example [1], [3], and methods devoted to finding optimal parameters of suspensions at constant harmonic excitations, see [2], [7] - [11]. However, none of the reviewed works utilize the ISO recommendations on evaluation of the admissible level of vertical accelerations [4]. In the present paper we apply the ISO recommendations to find optimal parameters of suspensions.

The method developed in this paper for finding optimal parameters of vehicle suspension, can be divide into several steps. First, we describe a model suitable for vibration analysis. We decided to consider a popular model in automotive engineering known as quarter-car model, see [2], [11]. Then, we find analytical solution of the vibrating model and impose restrictions according to the ISO standard [4]. And, finally, we construct an objective function and search for the global minimum of this function with respect to the spring stiffness and viscosity of the damper of the model.

To the best of our knowledge, no similar investigations have been made in this area in the literature. Minimized vibration level of the vehicle body leads to maximal ride comfort at the long-term exposure to vertical accelerations due vehicle movement along roads with different road profiles. Some numerical examples presented in this paper demonstrates application of the developed approach to the optimization of parameters of suspension system.

Manuscript received November 30, 2009

A. Kuznetsov, M. Mammadov, E. Hajilarov are with University of Ballarat, School of Information Technology and Mathematical Sciences, Mt. Helen Campus, Victoria, 3357 Australia, phone +61 413408133, email: alexeykuznetsov@students.ballarat.edu.au

I. Sultan is with University of Ballarat, School of Science and Engineering, Mt. Helen Campus, Victoria, 3357 Australia, phone +61 413408133
The paper is structured as follows. In the next section we make a brief introduction to the problem and consider general stages of the developed methodology. In the third section we perform numerical examples with real data of road profiles and suspension modelling. And, in the last section we formulate some conclusions upon presented results.

\section{FORMULATION OF OPTIMIZATION PROBLEM}

\subsection{Two mass model based on Kelvin elements and the corresponding second order equation.}

Kelvin element is the main type of viscoelastic elements used in modelling vehicle suspensions, tires, and human muscular-skeletal structure. Here we consider an advanced two-mass model that consists of two Kelvin elements. As it was mentioned above, such a model represents popular in vibration analysis quarter-car-model, where the upper mass $M_{2}$ represents a body of the vehicle and the lower mass $M_{1}$ is undamped mass of the wheel and suspension parts. The principle scheme of such model is given in Fig. 1.

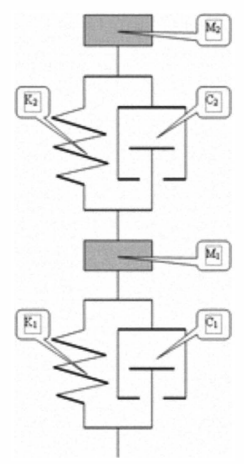

Fig. 1: Two mass model based on Kelvin elements

It is assumed that both springs and dashpots used in this model are weightless and have linear and constant with time response characteristics. The corresponding ODEs for the freely vibrating masses are the following:

$\left\{\begin{array}{l}M_{1} \ddot{x}_{1}+C_{1} \dot{x}_{1}+K_{1} x_{1}+C_{2} \dot{x}_{1}+K_{2} x_{1}-C_{2} \dot{x}_{2}-K_{2} x_{2}=0 \\ M_{2} \ddot{x}_{2}+C_{2} \dot{x}_{2}+K_{2} x_{2}-C_{2} \dot{x}_{1}-K_{2} x_{1}=0\end{array}\right.$

where $x_{1}$ and $x_{2}$ are deflections from the equilibrium position; $M_{1}, M_{2}$ are the masses, $C_{1}, C_{2}$ are the viscosity factors, and $K_{1}, K_{2}$ are the spring rates; all material constants are independent of $x_{1}, x_{2}, \dot{x}_{1}, \dot{x}_{2}$, and time $t$. The obvious general physical reasons imply 
$M_{q}>0, C_{q} \geq 0, K_{q} \geq 0$

\subsection{Deflection of the support and analytical solutions for the two mass model}

Herein, we construct analytical solution for the case when harmonic (vertical) deflection $u(t)=A \exp (i \omega t)$ is applied to the support of the lower element with mass $M_{1}$, where $A$ is the amplitude of harmonic deflections of the support and $\omega$ is the circular frequency of deflections. We shall also apply a constant gravity forces $M_{1} g$ and $M_{2} g$ to the corresponding masses. The governing second order equations for the considered case are:

$$
\left\{\begin{array}{l}
M_{1} \ddot{x}_{1}+C_{1} \dot{x}_{1}+K_{1} x_{1}+C_{2}\left(\dot{x}_{2}-\dot{x}_{1}\right)+K_{2}\left(x_{1}-x_{2}\right)= \\
C_{1} \dot{u}(t)+K_{1} u(t)-M_{1} g \\
M_{2} \ddot{x}_{2}+C_{2}\left(\dot{x}_{2}-\dot{x}_{1}\right)+K_{2}\left(x_{2}-x_{1}\right)=-M_{2} g
\end{array}\right.
$$

Introducing new variables $a=\dot{x}_{1}, b=\dot{x}_{2}$, and denoting

$$
\vec{X}=\left(x_{1}, x_{2}, a, b\right)^{T},
$$

we can transform (3) to the following system of four ODEs of the first order.

$$
\dot{\vec{X}}=\mathbf{G} \cdot \vec{X}+\vec{P}(t)
$$

where

$$
\begin{aligned}
& \mathbf{G}=\left(\begin{array}{cccc}
0 & 0 & 1 & 0 \\
0 & 0 & 0 & 1 \\
-\frac{K_{1}}{M_{1}}-\frac{K_{2}}{M_{1}} & \frac{K_{2}}{M_{1}} & -\frac{C_{1}}{M_{1}}-\frac{C_{2}}{M_{1}} & \frac{C_{2}}{M_{1}} \\
\frac{K_{2}}{M_{2}} & -\frac{K_{2}}{M_{2}} & \frac{C_{2}}{M_{2}} & -\frac{C_{2}}{M_{2}}
\end{array}\right), \\
& 0 \\
& \vec{P}(t)=\left(\begin{array}{c}
0 \\
\frac{C_{1}}{M_{1}} \dot{u}(t)+\frac{K_{1}}{M_{1}} u(t)-g \\
-g
\end{array}\right)
\end{aligned}
$$

Matrix $\mathbf{G}$ is known as the Jacobian of system (4), see [13]. Vector $\vec{P}(t)$ represents loading applied to both masses of the model.

The partial solution of (3) we are looking for, corresponds to the steady state vibrations of the masses of the considered model. Such a partial solution can be found in the following form (see, for example, [13]):

$$
\vec{X}(t)=(i \omega \mathbf{I}-\mathbf{G})^{-1} \cdot \vec{P}(t)
$$

While constructing the solution if a form (6) we need to consider two different cases: (i) a periodic solution related to harmonic (vertical) deflection $u(t)$ that excludes nonoscillating gravity forces $M_{1} g, M_{2} g$, and (ii) non-oscillating solution associated with gravity forces that excludes from the right-hand side all terms associated harmonic vibrations.

Thus, loading vector $\vec{P}(t)$ associated with periodic deflections $u(t)$ is the following:

$\vec{P}_{h}(t)=\left(\begin{array}{c}0 \\ 0 \\ \left(\frac{C_{1}}{M_{1}} \dot{u}(t)+\frac{K_{1}}{M_{1}} u(t)\right) \\ 0\end{array}\right)$

The solution of (6) for each of two masses of the model in the case of harmonic deflections (7) is as follows:

$\left\{\begin{array}{l}x_{1 h}(t)=\left(-\omega^{2} M_{2}+i \omega C_{2}+K_{2}\right) \frac{i \omega C_{1}+K_{1}}{d} A \exp (i \omega t) \\ x_{2 h}(t)=\left(i \omega C_{2}+K_{2}\right) \frac{i \omega C_{1}+K_{1}}{d} A \exp (i \omega t)\end{array}\right.$

where

$d=\omega^{4} M_{1} M_{2}+i \omega^{3}\left(-M_{1} C_{2}-M_{2} C_{1}-M_{2} C_{2}\right)+$

$\omega^{2}\left(-C_{1} C_{2}-M_{1} K_{2}-M_{2} K_{1}-M_{2} K_{2}\right)+$

$i \omega\left(C_{1} K_{2}+C_{2} K_{1}\right)+K_{1} K_{2}$.

Loading vector $\vec{P}(t)$ that corresponds to non-oscillating gravity forces $M_{1} g$ and $M_{2} g$ has the following representation:

$\vec{P}_{g}=\left(\begin{array}{c}0 \\ 0 \\ -g \\ -g\end{array}\right)$

so, the solution of (6) that corresponds to non-oscillating gravity loading vector (10) is the following:

$\left\{\begin{array}{l}x_{1 g}=g \frac{M_{1}+M_{2}}{K_{1}} \\ x_{2 g}=g \frac{M_{1} K_{2}+M_{2}\left(K_{1}+K_{2}\right)}{K_{1} K_{2}}\end{array}\right.$

As it was mentioned above, we are considering only steady state vibrations of the model. So, we are looking for partial solutions of the considered systems. Thus, summarizing periodical solutions (8) and non-oscillating solutions (11) we obtain the overall partial solution for deflections of masses:

$\left\{\begin{array}{l}x_{1}(t)=\left(-\omega^{2} M_{2}+i \omega C_{2}+K_{2}\right) \frac{i \omega C_{1}+K_{1}}{d} A \exp (i \omega t)+g \frac{M_{1}+M_{2}}{K_{1}} \\ x_{2}(t)=\left(i \omega C_{2}+K_{2}\right) \frac{i \omega C_{1}+K_{1}}{d} A \exp (i \omega t)+g \frac{M_{1} K_{2}+M_{2}\left(K_{1}+K_{2}\right)}{K_{1} K_{2}}\end{array}\right.$ 
and taking the second derivative of (12) we can find accelerations of each mass:

$\left\{\begin{array}{l}a_{1}(t)=-\omega^{2}\left(-\omega^{2} M_{2}+i \omega C_{2}+K_{2}\right) \frac{i \omega C_{1}+K_{1}}{d} A \exp (i \omega t) \\ a_{2}(t)=-\omega^{2}\left(i \omega C_{2}+K_{2}\right) \frac{i \omega C_{1}+K_{1}}{d} A \exp (i \omega t)\end{array}\right.$

Thus, we can point out the following notes:

- Formula (13) can be used for evaluation of vertical accelerations of vibration for fixed single frequency $\omega$.

- As long as we consider steady state vibrations, we will operate with the real part of acceleration $a_{1}(t), a_{2}(t): \operatorname{Re}\left(a_{1}(t)\right), \operatorname{Re}\left(a_{2}(t)\right)$.

\subsection{Vibration evaluation and the objective function construction}

According to the ISO 2631 standard [4], vibration evaluation includes measurements of the weighted root-meansquare (r.m.s) accelerations that will be defined by $E_{w}$. In general case, vibration spectrum consists of $n$ independent bands with the corresponding frequencies $\omega_{i}$, where $i=1,2, \ldots n$. Then, according to methodology provided by ISO, weighting factor $W_{i}, i=1,2, \ldots n$ should be applied to each frequency $\omega_{i}$. In further applications, values of $W_{i}$ will be taken form ISO 2631. Thus, we get number of acceleration functions $\alpha_{i}$ defined by (13) for each frequency $\omega_{i}$.

Standard ISO 2631 defines the r.m.s weighted acceleration $E_{w}$ by the following formula:

$E_{w}=\left(\frac{1}{T} \int_{0}^{T} b_{w}^{2}(t) d t\right)^{\frac{1}{2}}$

where $T$ is a duration of measurement, and $b_{w}(t)$ is the frequency weighted acceleration:

$b_{w}(t)=\left(\sum_{i=1}^{n}\left(W_{i} \alpha_{i}(t)\right)^{2}\right)^{\frac{1}{2}}$

Combining (14) and (15) we obtain the following expression:

$E_{w}=\left(\frac{1}{T} \int_{0}^{T} \sum_{i}\left(W_{i} \alpha_{i}(t)\right)^{2} d t\right)^{\frac{1}{2}}=\left(\sum_{i} W_{i}^{2} A_{i}(T)\right)^{\frac{1}{2}}$

where

$A_{i}(T)=\frac{1}{T} \int_{0}^{T} \alpha_{i}^{2}(t) d t$

and

$\alpha_{i}(t)=\operatorname{Re}\left(a_{2 i}(t)\right)$

In (18), we apply ISO methodology of evaluation of vibration exposure for upper mass $M_{2}$ only, as we focus on vibration analysis of the body of the vehicle for each $i$ band of the vibration spectrum. Also, we take into account only steady state vibrations by using the real part of the acceleration (13).

Herein, the main target is to find such parameters of spring stiffnesses $K_{1}, K_{2}$ and damper viscosities $C_{1}, C_{2}$ that ensure the minimal value for r.m.s weighted acceleration $E_{w}$ for upper mass. This leads to the following objective function to be minimized:

$E_{w}\left(K_{1}, K_{2}, C_{1}, C_{2}\right)=\left(\sum_{i}^{n} W_{i}^{2} \frac{1}{T} \int_{0}^{T} \operatorname{Re}\left(a_{2 i}(t)\right)^{2} d t\right)^{\frac{1}{2}}$

\subsection{Steady-state vibrations}

As it was noticed above, we are focusing on vibration of the body of the vehicle. So, we continue vibration analysis for upper mass $M_{2}$ only. Also, we mentioned in section 2.2 that steady state response corresponds to the partial solution of (3). Then, for steady state vibrations the problem of minimization (19) can be derived in the following manner using the real part of the acceleration (13) for each $i$ band of excitation:

$\operatorname{Re}\left(a_{2 i}(t)\right)=-Q_{i} \frac{H_{i} K_{2}+\omega_{i} C_{2} L_{i}}{Q_{i}^{2}+R_{i}^{2}}-R_{i} \frac{L_{i} K_{2}-\omega_{i} C_{2} H_{i}}{Q_{i}^{2}+R_{i}^{2}}$

where

$$
\begin{aligned}
& H_{i}=\mathrm{A}_{i} \omega_{i}^{3} C_{1} \cos \left(\omega_{i} t\right)+\mathrm{A}_{i} \omega_{i}^{2} K_{1} \sin \left(\omega_{i} t\right) \\
& L_{i}=\mathrm{A}_{i} \omega_{i}^{2} K_{1} \cos \left(\omega_{i} t\right)+\mathrm{A}_{i} \omega_{i}^{3} C_{1} \sin \left(\omega_{i} t\right) \\
& Q_{i}=\omega_{i} C_{1} K_{2}+\omega_{i} C_{2} K_{1}-\omega_{i}^{3} C_{1} M_{2}-\omega_{i}^{3} C_{2} M_{1}-\omega_{i}^{3} C_{2} M_{2} \\
& R_{i}=K_{1} K_{2}-\omega_{i} C_{1} C_{2}-\omega_{i}^{2} K_{1} M_{2}-\omega_{i}^{2} K_{2} M_{1}-\omega_{i}^{2} K_{2} M_{2}+\omega_{i}^{4} M_{1} M_{2}
\end{aligned}
$$

In (21), $A_{i}$ is an amplitude of harmonic deflections of the support for $i$ frequency band.

Applying integration procedure (17) - (20) we get some terms involving $\sin \left(\omega_{i} T\right)$ and $\cos \left(\omega_{i} T\right)$. Obviously, considering large time periods of driving; that is $T \rightarrow \infty$, the terms associated with $\sin \left(\omega_{i} T\right)$ and $\cos \left(\omega_{i} T\right)$ will converge to zero. Therefore, $A_{i}(T)$ will be mostly dependent on terms which are not linked to $\sin \left(\omega_{i} T\right)$ and $\cos \left(\omega_{i} T\right)$. That allows us to consider only the limits $\lim _{T \rightarrow \infty} A_{i}(T)$ instead of $A_{i}(T)$ :

$\left\{\lim _{T \rightarrow \infty} A_{i}(T)=\frac{\omega_{i}^{4} \mathrm{~A}_{i}^{2}\left(\omega_{i}^{2} c_{1}^{2}+k_{1}^{2}\right)\left(\omega_{i}^{2} c_{2}^{2}+k_{2}^{2}\right)}{2\left(R_{i}^{2}+Q_{i}^{2}\right)}\right.$

Thus, the objective function (19) can be approximated by using (22) in the following manner:

$$
F\left(K_{1}, K_{2}, C_{1}, C_{2}\right)=\left[\sum_{1}^{n}\left(\frac{\omega_{i}^{4} \mathrm{~A}_{i}^{2}\left(\omega_{i}^{2} c_{1}^{2}+k_{1}^{2}\right)\left(\omega_{i}^{2} c_{2}^{2}+k_{2}^{2}\right)}{2\left(R_{i}^{2}+Q_{i}^{2}\right)} W_{i}^{2}\right)\right]^{\frac{1}{2}}
$$


where $n$ is number of frequencies in vibration spectrum. Now, the optimization problem can be formulated as follows:

Minimize: $F\left(K_{1}, K_{2}, C_{1}, C_{2}\right)$

Subject to: $K_{1}, K_{2}, C_{1}, C_{2} \in B$

Here $B$ is the box describing the range for values of variables. We note that, (24), (25) involve steady solutions only and, in contrast of (19), the last problem does not contain parameter $T$.

Performing optimization task, we are looking for a global solution. In the calculations performed for examples considered in the subsequent section, we used the global optimization algorithm AGOP, introduced in $[5,6]$.

\section{NUMERICAL EXAMPLES}

Herein we performed Power Spectral Density calculations of five reference sections of the Northern Highway and Princess Highways from minimal speed limit on the highway $70 \mathrm{~km} / \mathrm{h}$ to maximal speed limit $110 \mathrm{~km} / \mathrm{h}$. We used measurements of highway profile data presented by research group of Swinburn University. In Fig. 2, for reference purposes, we show Power Spectral Densities of of Northern and Princess highways (N11) at speeds $70 \mathrm{~km} / \mathrm{h}$ and $110 \mathrm{~km} / \mathrm{h}$. All the considered sections have different quality profiles that can be roughly estimated while looking at their Power Spectral Densities. However, such a visual method allows to predict in advance which road will be the smoothest one.

Some notations of the experimental part of research: the weighting factors $W_{i}$ corresponding to each evaluated frequency band $\omega_{i}$ were taken from the ISO 2631. Also, to avoid smooth in calculation, we counted frequencies $\omega_{i}$ having ISO 2631 weighting factor $W_{i}$ more than $10 \%$. Thus, we consider frequencies $\omega_{i}$ from the range $1-80 \mathrm{~Hz}$. All the values of parameters of the considered quarter-car model are taken in respect of [12], where the tyre of a wheel is considered with no damping property $c_{1}$. Also we assume that both masses $m_{1}=20 \mathrm{~kg}$ and $m_{2}=300 \mathrm{~kg}$ are constant. The stiffnesses of springs here are taken $k_{1} \in[135000,230000](N / m), \quad k_{2} \in[10000,25000](N / m)$ and viscosity of damper is $c_{2} \in[1000,6000](H \mathrm{sec} / \mathrm{m})$. Values for the spring $k_{1}$ are stiffness of the car's tyre, while it low pressured-16PSI and over pressured - 44PSI. The limits of the box of the spring $k_{2}$ and damper $c_{2}$ are determined from the engineering point of view of suspension deflection, and using [12] as reference. Thus, we can represent box $B=[135000,230000],[10000,25000] \times[1000,6000]$.

The computational results for the acceleration of mass for quarter-car model are presented in Tables 3.1, and 3.2 with different speeds of the vehicle. According to the standard ISO 2631, there are three final criteria, which evaluate the exposure of the vibration transmitted to human. These ISO criteria show how many hours a human can feel vibration exposure with no health risks, with potential health risks, and when the health risks are likely. In this paper we mentioned values corresponding to "no health risk" criterion, as it is the most strict condition. For better presentation, ISO curve that defines limits of vibration exposures for different acceleration levels is shown in Fig. 3.

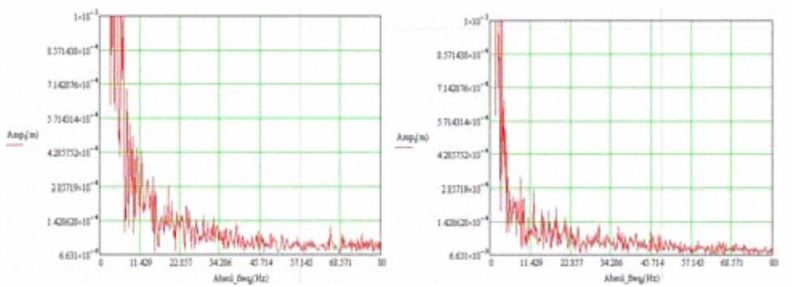

Fig. 2: Spectral Densities of the reference section of the Northern Highway $\mathrm{N} 11$ at speed $70 \mathrm{~km} / \mathrm{h}$ (left plot) and $110 \mathrm{~km} / \mathrm{h}$ (right plot) 
TABLE 3.1. THE MINIMUM VALUES OF WEIGHTED ACCELERATIONS (M/SEC ${ }^{2}$ ) OF OBJECTIVE FUNCTION ACHIEVED BY FOUND OPTIMAL PARAMETERS OF DAMPER $c_{2}$ AND SPRING $k_{2}$ OF SUSPENSION, AND TYRE STIFFNESS $k_{1}$ OF THE QUARTER- CAR MODEL FOR REFERENCE SECTIONS OF HIGHWAYS:

\begin{tabular}{|c|c|c|c|c|c|}
\hline $\begin{array}{c}\text { Vehicle } \\
\text { speed } \\
(\mathrm{km} / \mathrm{h})\end{array}$ & $\begin{array}{c}\text { Northern } \\
\text { highway } \\
\text { section } \\
\mathrm{N} 11 \\
(500 \mathrm{~m})\end{array}$ & $\begin{array}{c}\text { Princess } \\
\text { Highway } \\
\text { section } \\
\text { PER5A } \\
(600 \mathrm{~m})\end{array}$ & $\begin{array}{c}\text { Princess } \\
\text { Highway } \\
\text { section } \\
\text { PER3A } \\
(100 \mathrm{~m})\end{array}$ & $\begin{array}{c}\text { Princess } \\
\text { Highway } \\
\text { section } \\
\text { PEF8 } \\
(500 \mathrm{~m})\end{array}$ & $\begin{array}{c}\text { Princess } \\
\text { Highway } \\
\text { section } \\
\text { PEF12 } \\
(200 \mathrm{~m})\end{array}$ \\
\hline 70 & 0.124178 & 0.059687 & 0.274791 & 0.145587 & 0.197194 \\
\hline 75 & 0.137341 & 0.065509 & 0.282597 & 0.156769 & 0.206259 \\
\hline 80 & 0.135327 & 0.065463 & 0.345636 & 0.165585 & 0.210049 \\
\hline 85 & 0.140906 & 0.070024 & 0.350856 & 0.170265 & 0.221254 \\
\hline 90 & 0.146597 & 0.075152 & 0.366376 & 0.181341 & 0.224987 \\
\hline 95 & 0.156623 & 0.080017 & 0.384248 & 0.190326 & 0.231336 \\
\hline 100 & 0.173629 & 0.080441 & 0.423494 & 0.19978 & 0.237903 \\
\hline 105 & 0.177879 & 0.084598 & 0.49896 & 0.207804 & 0.296356 \\
\hline 110 & 0.187191 & 0.102431 & 0.503761 & 0.223344 & 0.299341 \\
\hline
\end{tabular}

TABLE 3.2. HEALTH GUIDANCE CAUTION ZONES (B2) OF ISO 2631-1: TIME LIMITS (HOURS) OF VIBRATION EXPOSURE WITH NO HEALTH RISK CONDITIONS FOR THE NUMERICAL RESULTS FROM TABLE 3.1

\begin{tabular}{|c|c|c|c|c|c|}
\hline $\begin{array}{l}\text { Vehicle } \\
\text { speed } \\
(\mathrm{km} / \mathrm{h})\end{array}$ & $\begin{array}{c}\text { Northern } \\
\text { highway } \\
\text { section } \\
\text { N11 }\end{array}$ & $\begin{array}{c}\text { Princess } \\
\text { Highway } \\
\text { section } \\
\text { PER5A }\end{array}$ & $\begin{array}{c}\text { Princess } \\
\text { Highway } \\
\text { section } \\
\text { PER3A }\end{array}$ & $\begin{array}{c}\text { Princess } \\
\text { Highway } \\
\text { section } \\
\text { PEF8 }\end{array}$ & $\begin{array}{c}\text { Princess } \\
\text { Highway } \\
\text { section } \\
\text { PEF12 }\end{array}$ \\
\hline 70 & No limit & No limit & $\begin{array}{c}\text { Up to } 20 \\
\text { hours }\end{array}$ & No limit & No limit \\
\hline 75 & No limit & No limit & $\begin{array}{l}\text { Up to } 19 \\
\text { hours }\end{array}$ & No limit & No limit \\
\hline 80 & No limit & No limit & $\begin{array}{l}\text { Up to } 13 \\
\text { hours }\end{array}$ & No limit & No limit \\
\hline 85 & No limit & No limit & $\begin{array}{c}\text { Up to } 12 \\
\text { hours }\end{array}$ & No limit & No limit \\
\hline 90 & No limit & No limit & $\begin{array}{c}\text { Up to } 12 \\
\text { hours }\end{array}$ & No limit & No limit \\
\hline 95 & No limit & No limit & $\begin{array}{l}\text { Up to } 12 \\
\text { hours }\end{array}$ & No limit & No limit \\
\hline 100 & No limit & No limit & $\begin{array}{l}\text { Up to } 11 \\
\text { hours }\end{array}$ & No limit & No limit \\
\hline 105 & No limit & No limit & $\begin{array}{l}\text { Up to } 6 \\
\text { hours }\end{array}$ & No limit & $\begin{array}{c}\text { Up to } 18 \\
\text { hours }\end{array}$ \\
\hline 110 & No limit & No limit & $\begin{array}{l}\text { Up to } 6 \\
\text { hours }\end{array}$ & No limit & $\begin{array}{c}\text { Up to } 18 \\
\text { hours }\end{array}$ \\
\hline
\end{tabular}

No limit" value means that vibration exposure is not an issue for limitations of driving. In this case, probable issue can be natural fatigue due to long term riding.

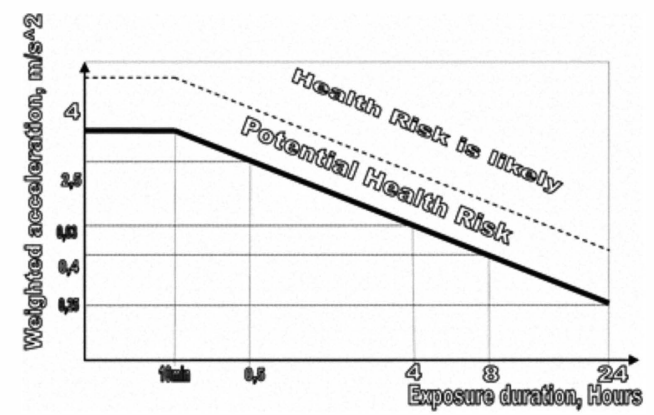

Fig. 3: ISO 2631: maximum vibration exposure time that corresponds to No Health Risk condition, depending on the target function value (bold curve)
TABLE 3.3. The OPTIMAL PARAMETER VALUES $c_{2}$ AND $k_{2}$ OF SUSPENSION AND TYRE STIFFNESS $k_{1}$ OF THE QUARTER- CAR MODEL FOR THE CONSIDERED SECTIONS OF HIGHWAYS

\begin{tabular}{|c|c|c|c|c|c|c|}
\hline $\begin{array}{c}\text { Vehicl } \\
\text { e speed } \\
\text { range } \\
(\mathrm{km} / \mathrm{h})\end{array}$ & $\begin{array}{c}\text { Optimal } \\
\text { values of } \\
\text { the } \\
\text { parameters }\end{array}$ & $\begin{array}{c}\text { Norther } \\
\mathbf{n} \\
\text { highway } \\
\text { section } \\
\text { N11 }\end{array}$ & $\begin{array}{c}\text { Princess } \\
\text { Highway } \\
\text { section } \\
\text { PER5A }\end{array}$ & $\begin{array}{c}\text { Princess } \\
\text { Highway } \\
\text { section } \\
\text { PER3A }\end{array}$ & $\begin{array}{c}\text { Princess } \\
\text { Highway } \\
\text { section } \\
\text { PEF8 }\end{array}$ & $\begin{array}{c}\text { Princess } \\
\text { Highway } \\
\text { section } \\
\text { PEF12 }\end{array}$ \\
\hline \multirow{7}{*}{$70-110$} & $k_{1}(\mathrm{H} / \mathrm{m})$ & 135000 & 135000 & 135000 & 135000 & 135000 \\
\cline { 2 - 7 } & $k_{2}(\mathrm{H} / \mathrm{m})$ & 10000 & 10000 & 10000 & 10000 & 10000 \\
\cline { 2 - 7 } & $\begin{array}{c}c_{2} \\
(\mathrm{H} \mathrm{sec} / \mathrm{m})\end{array}$ & 1000 & 1000 & 1000 & 1000 & 1000 \\
\hline
\end{tabular}

Looking at the results in Table 3.3, we can find some important tendencies and observations: as we can see, to achieve the best comfort performance in vehicle on highways, the tyres should have minimal stiffness, as parameter $k_{1}$ remains at minimum in all the considered cases, and suspension system also required minimal stiffness of the spring $k_{2}$. Damping factor $c_{2}$ has lowest values of the considered box $B$. So, it means that highway speed limit require the softest suspension settings for improved comfort level. This phenomenon will be analysed further, using more detailed model of the system Human - Vehicle - Road that will include a bio-mechanical model of a driver. That will allow better understanding of influencing vibrations on a driver's body in moving vehicle.

From engineering point of view, it is very important to observe the influence of each parameter on the comfort level. In Figure 4 it is shown influence of stiffness of the tyre $k_{1}$, suspension spring stiffness $k_{2}$ and damping factor $c_{2}$ on the comfort level for Northern and Princess highway sections. Weighted accelerations are on vertical axes, and horizontal axes are linked to boundaries of the box $B=[135000,230000],[10000,25000] \times[1000,6000]$.

Analysing plots on Fig. 4, we can make the following important observations valid for any speed driven on highways: stiffness of the tyres doesn't influence much on the comfort level of the vehicle; stiffness of the springs in suspension influences the comfort level considerably, and comfort level is extremely sensitive to the damping factors (damper viscosities).

As far as we know, the quarter-car model that describes vibration influence on comfort level, defined by ISO standard "Mechanical vibration and shock - Evaluation of human exposure to whole-body vibration", is a new methodology presented for the first time in this paper. However, some researches have been done in respect to particular engineering measurements and techniques where vibration analysis is associated with personal intuitive of engineer's experience. A lot of opinions regarding comfort level are based on numerical methods and results with charging about comfort level intuitively. Such opinions on suspension tuning are possible to see in some past engineering 
guides, suggesting adjustments of the suspension systems that differ from analytical results obtained in this paper. For example, in [14] it is stated that (i) "moving with stiff tyres along roads with a neat mirror-like surface can be more comfortable than with soft tyres." Here, our results show that tyre should have minimal stiffness for best comfort performance, although tyre stiffness doesn't influence much on comfort level in the vehicle on highways; (ii) "analysing formulae that determine dependence of the ride smoothness (the latter is associated with accelerations) upon parameters of the linear model, reveals that irrelevant to the road spectra, decreasing of the spring stiffness is favourable for the ride comfort." Our results prove this statement for all considered highway sections at all speeds from $70 \mathrm{~km} / \mathrm{h}$ to $110 \mathrm{~km} / \mathrm{h}$; (iii)"it was observed that a road micro-profile considerably influences the optimal parameters of the damper, and the optimal damper viscosity is increased with the speed of the vehicle." Looking at the corresponding plots on Fig.4, we can see that either for minimal speed on highway $70 \mathrm{~km} / \mathrm{h}$, or maximal allowed speed $110 \mathrm{~km} / \mathrm{h}$, the damper viscosity should remain at minimal values to provide the lowest accelerations of the vehicle's body.

Here it is important to mention that current research is targeted to improve comfort level for a driver and passengers of the vehicle in terms of health conditions, defined by standard ISO 2631. Analysis of the vehicle behaviour on the road requires consideration of the particular suspension type with the kinematic schemes that include horizontal and lateral deflections. We have to notice, that we did not include consideration of handling and steering problems into research scope, as together with health risk criteria, considered in this paper, the problem of optimization of the steering parameters leads to multi-criterial optimization. As far as we know, optimization of an objective function of both improved comfort level and advanced steering performance is yet to be developed.

\section{CONCLUSIONS}

The presented paper makes a contribution to vibration analysis in automotive engineering by evaluation of the vibration exposure transmitted from a road profile to a driver or passenger of the vehicle, using methodology of the standard ISO 2631. Particularly, obtained numerical results and tendencies of influence parameters of suspension system on comfort level are well expected from the engineering point of view. Therefore, we can conclude that the considered model is suitable for vibration analysis and optimization of suspension system of vehicle.

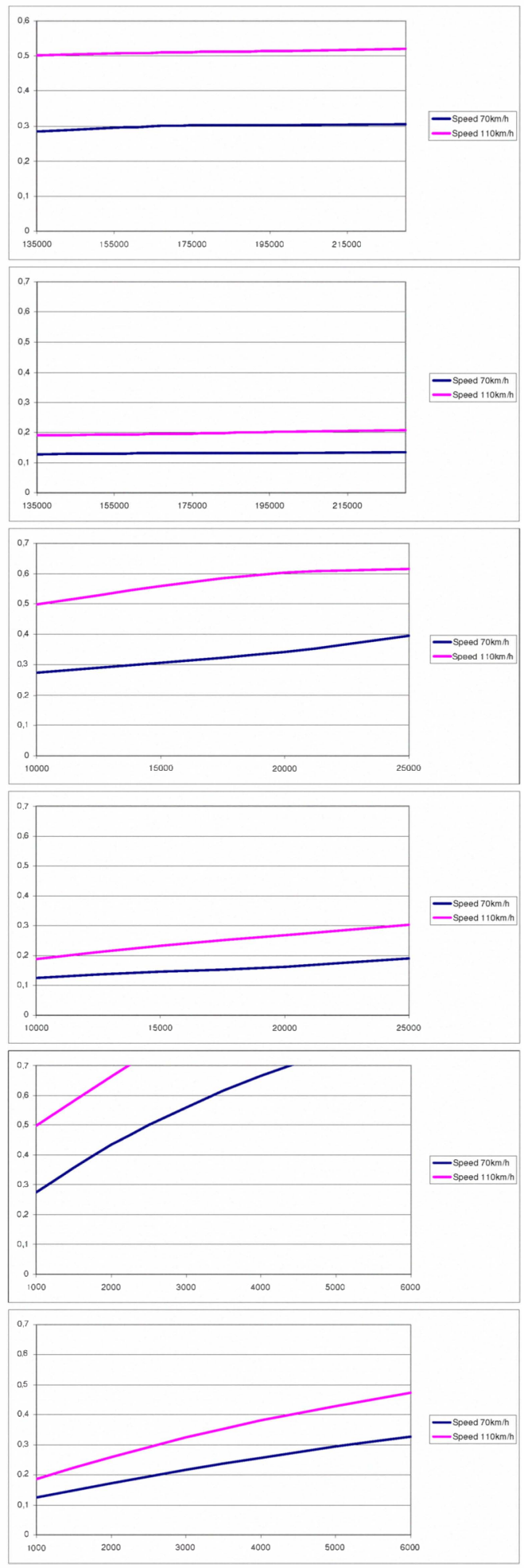

Fig. 4. Influence of tyre stiffness (first two plots), suspension spring stiffness (third and fourth plots) and damping factor (last two plots) on ISO 2631 weighted accelerations for reference sections of Northern and Princess highways correspondingly. Pink lines show changed levels of accelerations at top speed $110 \mathrm{~km} / \mathrm{h}$ and blue lines show changed levels of acceleration at minimal considered speed $70 \mathrm{~km} / \mathrm{h}$ 


\section{REFERENCES}

[1] Chen P.C., Huang A.C., Adaptive Multi-surface Sliding Control of Hydraulic Active Suspension Systems, Journal of Vibration and Control, 2005, No.11

[2] Georgiou G., Verros G., Natsiavas S., Multi-objective Optimization of Quarter-car Models with a Passive or Semi-active Suspension System, Vehicle System Dynamics, 2007, vol.45, No.1, pp. 77-92.

[3] Harris' Shock and Vibration Handbook, $5^{\text {th }}$ edition, Editors C.M. Harris and A.G. Piersol, McGraw-Hill, N.Y., 2002.

[4] ISO 2631-1:1997, "Mechanical Vibration and Shock - Evaluation of human exposure to whole-body vibration - Part 1".

[5] Mammadov, M. A., Rubinov, A. M., Yearwood, J.: Dynamical systems described by relational elasticities with applications to global optimization. In: V. Jeyakumar and A. Rubinov (Eds.) Continuous Optimisation: Current Trends and Applications, Springer, 2005, pp. 365387.

[6] Mammadov, M.A.: A new global optimization algorithm based on dynamical systems approach. In: A. Rubinov and M. Sniedovich (eds) $6^{\text {th }}$ International Conference on Optimization: Techniques and Applications, Ballarat, Australia, 2004.

[7] Metallidis P., Verros G., Natsiavas S., Fault Detection and Optimal Sensor Location in Vehicle Suspensions, Journal of Vibration and Control, 2003, No.9

[8] Papalukopoulos C., Giadopulos D., Natsiavas S., Dynamics of Large Scale Vehicle Models Coupled with Driver Biodynamic Models, $5^{\text {th }}$ GRACM International Congress on Computational Mechanics, Limassol, 2005.

[9] Papalukopoulos C., Theodosiou C., Natsiavas S., Nonlinear Dynamics of Vehicle Models Coupled with Biodynamic Passenger Models, $2^{\text {nd }}$ International Conference on Nonlinear Normal Modes and Localization in Vibrating Systems, Samos, 2006.

[10] Verros G., Goudas H., Natsiavas S., Dynamics of Large Scale Vehicle Models Using ADAMS/FLEX, International ADAMS User Conference, 2000.

[11] Verros G., S. Nastiavas S., Papadimitriou C., Design Optimization of Quarter-car Models with Passive and Semi-active Suspensions under Random Road Excitation, Journal of Vibration and Control, 2005, No. 1, pp. 581-606.

[12] Werner S., White noise excitation of road vehicle structures, Sadhana, 2007, vol.31, Part 4, pp 487-503

[13] Zwillinger D., Handbook of Differential Equations. $3^{\text {rd }}$ edition, Academic Press, N.Y., 1997.

[14] Khachaturov A. Dynamics of the system Road-Tyre-Vehicle-Driver (in Russian), Moscow, 1976 